\title{
An improved method for evaluating the rotational speed stability of a hydro-viscous clutch in mixed lubrication
}

\author{
Shou-Wen YAO ${ }^{1,2}$, Qian LIU ${ }^{1, *}$, Hong-Wei CUI ${ }^{3}$, Shan-Shan FENG ${ }^{1}$ \\ ${ }^{1}$ School of Mechanical Engineering, Beijing Institute of Technology, Beijing 100081, China \\ ${ }^{2}$ National Key Laboratory of Vehicular Transmission, Beijing Institute of Technology, Beijing 100081, China \\ ${ }^{3}$ School of Mechanical Engineering, Taiyuan University of Technology, Taiyuan 030024, China \\ Received: 19 May 2014 / Revised: 12 July 2014 / Accepted: 02 December 2014 \\ C The author(s) 2014. This article is published with open access at Springerlink.com
}

\begin{abstract}
Rotational speed stability is an important evaluation indicator of the performance of a hydro-viscous clutch (HVC). To improve the rotational speed stability of HVCs in mixed lubrication and the running condition of the friction pairs, the speed stability of an HVC in mixed lubrication was studied. To this end, the friction coefficients of both copper-based and paper-based friction pairs were experimentally tested using an MM1000-III wet friction machine. Theoretically, a torsional vibration model of the system is presented. The phase plane analysis method is applied to evaluate the stability of the torsional vibration model, where a critical negative gradient (CNG) is defined. The results show that the friction coefficient in mixed lubrication is an important parameter for the stability of the rotational speed. The system will be unstable when the negative gradient of the friction coefficient-slip speed is larger than the CNG. According to the definition of the CNG, suggestions regarding choice of friction pairs are made to improve the rotational speed stability of an HVC in mixed lubrication.
\end{abstract}

Keywords: Hydro-viscous clutch; mixed lubrication; speed stability; negative gradient of friction coefficientslipping speed; torsional vibration model; critical negative gradient

\section{Introduction}

A hydro-viscous clutch (HVC) can adjust the output rotational speed by changing the thickness of the oil film between friction discs and separator discs, and has advantages, such as energy savings, stepless speed adjustments, and overload protection. Thus, HVCs have been widely used for not only the soft starting of conveyor belts for mine and wharf applications but also the fan drive of tracked vehicles [1-3].

The frictional condition of the friction pair of an HVC can be divided into full film lubrication, mixed lubrication, and static friction. In full film lubrication, the mating surfaces of the friction pair are separated by a relatively thick fluid film, and the torque

\footnotetext{
* Corresponding author: Qian LIU.
}

E-mail: liuqian.bit@gmail.com transmitted from engine to load is a hydrodynamic torque. In mixed lubrication, the mating surface of the friction pair is supported by the combination of a hydrodynamic film and asperity contacts [4], thus, the torque transmitted from engine to load can be divided into two parts: the hydrodynamic torque and the asperity torque [5].

Patir et al. [6] applied an average flow model to study the effects of three-dimensional roughness in mixed lubrication. Lu et al. [7,8] analyzed a journal bearing in mixed lubrication, and applied a Stribeck curve prediction of the journal bearing and evaluated the frictional characteristics of its dimple effect. Wang et al. $[9,10]$ studied mixed lubrication problems in point contact, and found that surface features, such as roughness amplitude and patterns, may have a significant effect on the critical speed of transition 
from hydrodynamic to mixed lubrication. Masjedi et al. [11] derived formulae for predicting the asperity load ratio of a rough interface under line-contact elasto-hydrodynamic lubricated (EHL) conditions.

The torque and rotational speed of the driveline will be unstable when the relative rotational speed of the friction disc and separator disc is small. Speed stability is one of the key evaluations of an HVC. An unstable output rotational speed will reduce the efficiency and expected energy-savings of an HVC as well as results in less secure power transmission [12].

Berger [13] studied the characteristics of torque transmission of an HVC using a finite element approximate analysis model. Huron [14] performed numerical simulation tests based on an SAE No. 2 wet friction test machine, and concluded that stable input excitation results in system vibration. Gao et al. [15] studied the sliding process of an HVC using Berger's analysis model, which focused on torque vibration and the influence of sliding time on temperature increase during the sliding process. Cameron et al. [5] identified the negative friction gradient to explain friction-induced self-excited vibrations between the clutch interface.

Studies related to mixed lubrication or methodologies can be used in analyzing the rotational speed stability of HVCs in mixed lubrication. This paper focuses on the rotational speed stability of HVCs in mixed lubrication, which has not been fully studied and explained. The speed stability of HVCs in mixed lubrication is studied theoretically and experimentally to improve the rotational speed stability of HVCs in mixed lubrication and the running condition of friction pairs.

The friction coefficients of both copper-based and paper-based friction pairs are evaluated using braking tests to establish their frictional characteristics. The torsional vibration model of the system is presented, and the phase plane analysis method is applied to reveal the effects of friction on the rotational speed stability of HVCs in mixed lubrication.

\section{Tests of friction coefficient versus slipping speed}

The friction coefficient of the friction pairs is not a constant value, which relates not only to the material characteristics, but also to the slipping speed between the friction discs and separator discs.

For the experimental part of this study, the MM1000-III wet friction machine shown in Fig. 1(a) was used, which can operate a rotating ring-on-ring braking test. After setting the simulated moment of inertia, the highest rotational speed of the rotating chuck, and the positive pressure of the static chuck during the brake operation, a braking test was performed automatically with the MM1000-III. The axial force was detected with a pressure sensor and the frictional torque was measured by the pulling force sensor shown in Fig. 1(b). Thus, the friction coefficient of the friction pair was calculated using the frictional torque divided by the product of the mean radius

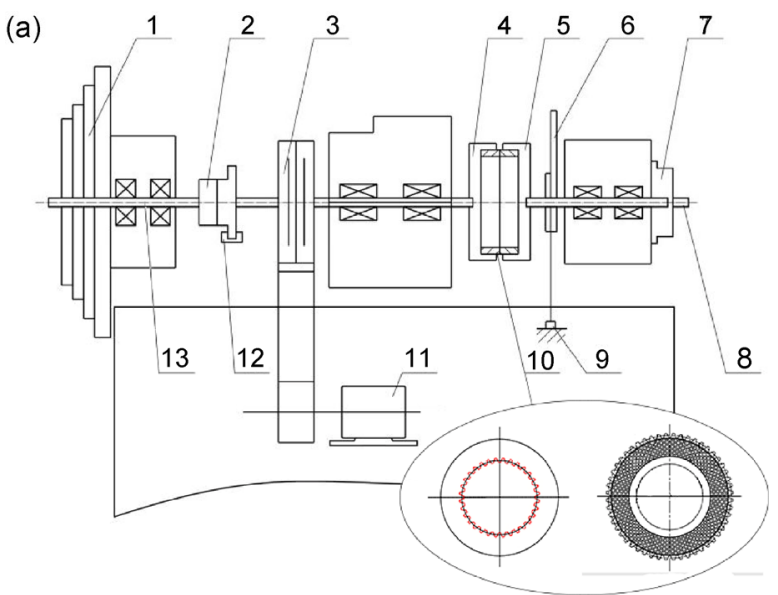

(b)

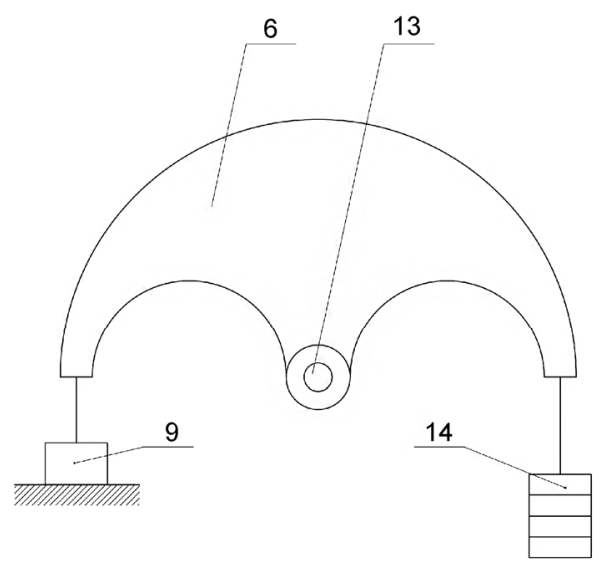

Fig. 1 Schematic of the MM1000-III wet friction tester: 1-Inertia disc; 2-Flange of speed measurement; 3-Clutch; 4-Rotating chuck; 5-Static chuck; 6-Force arm; 7-Air cylinder; 8-Pressure sensor; 9-Pulling force sensor; 10-Friction pair; 11-Main motor; 12 - Rotational speed sensor; 13-Shaft; 14-Weights. 
and the axial force. During the test, the friction disc is fixed on the rotating chuck and the separator disc on the static chuck to ensure that the effects of the oil grooves on the friction disc are close to actual working conditions.

We conducted five tests under the same conditionsthe same friction pair and oil, the same temperature, and the same relative rotational speed beginning at $4,500 \mathrm{rpm}$. The tests are repeatable, when the following is considered: The friction pair is of the same material, size, and with an equivalent oil groove with test sample shown in Fig. 2, and the oil type is the same.

Table 1 lists the materials used in the tests. Friction disc 1 and Separator disc 1 make up the copper-based friction pair, whereas Friction disc 2 and Separator disc 2 are the paper-based friction pair. Both friction pairs have the same inner and outer diameters, friction lining thickness, and oil groove. The friction pair is used to perform the test after conducting a run-in. The friction lining remains on its substrate after completion of the tests, and the influence of the substrate is ignored during testings.

The friction coefficient-slipping speed curves of the copper-based and paper-based friction pairs are shown in Fig. 3. In addition, the derivative of the friction coefficient-slipping speed curves of both friction pairs are shown in Fig. 4.
In full film lubrication, the mating surface of the friction pair is supported by the hydrodynamic film, and the torque is transmitted from engine to load via the hydrodynamic torque. However, in mixed lubrication, the mating surface of the friction pair is supported by a combination of the hydrodynamic film and asperity contacts, and the torque transmitted from engine to load can be divided into two parts: the hydrodynamic torque and the asperity torque. The different lubrication mechanism of full film lubrication and mixed lubrication causes the derivative of the friction coefficient-slipping speed to change from positive to negative, as shown in Fig. 4.

Thus, Figs. 3 and 4 show that both copper-based and paper-based friction pairs experience conditions from full film lubrication, to mixed lubrication, to static friction. The critical point in Fig. 4, as well as the corresponding turning point in Fig. 3, is considered to be the boundary between full film lubrication and mixed lubrication. For the copper-based friction pair, as the relative rotational speed decreases, the friction coefficient decreases rapidly at first in mixed lubrication and increases slowly after the turning point in full film lubrication. For the paper-based friction pair, as the relative rotational speed decreases, the friction coefficient decreases slightly at first in mixed lubrication and remains nearly constant above 2,000 rpm.

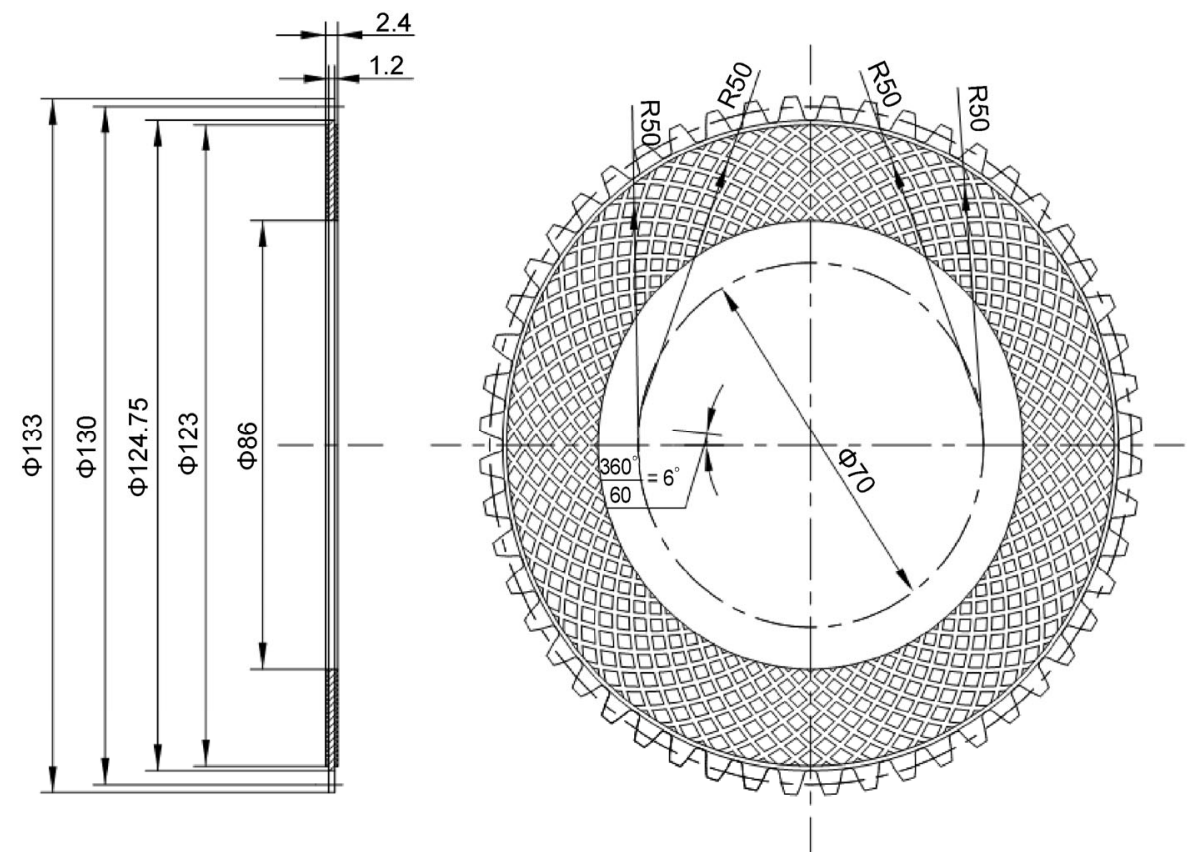

Fig. 2 Friction disc sample. 
Table 1 Materials used in the tests.

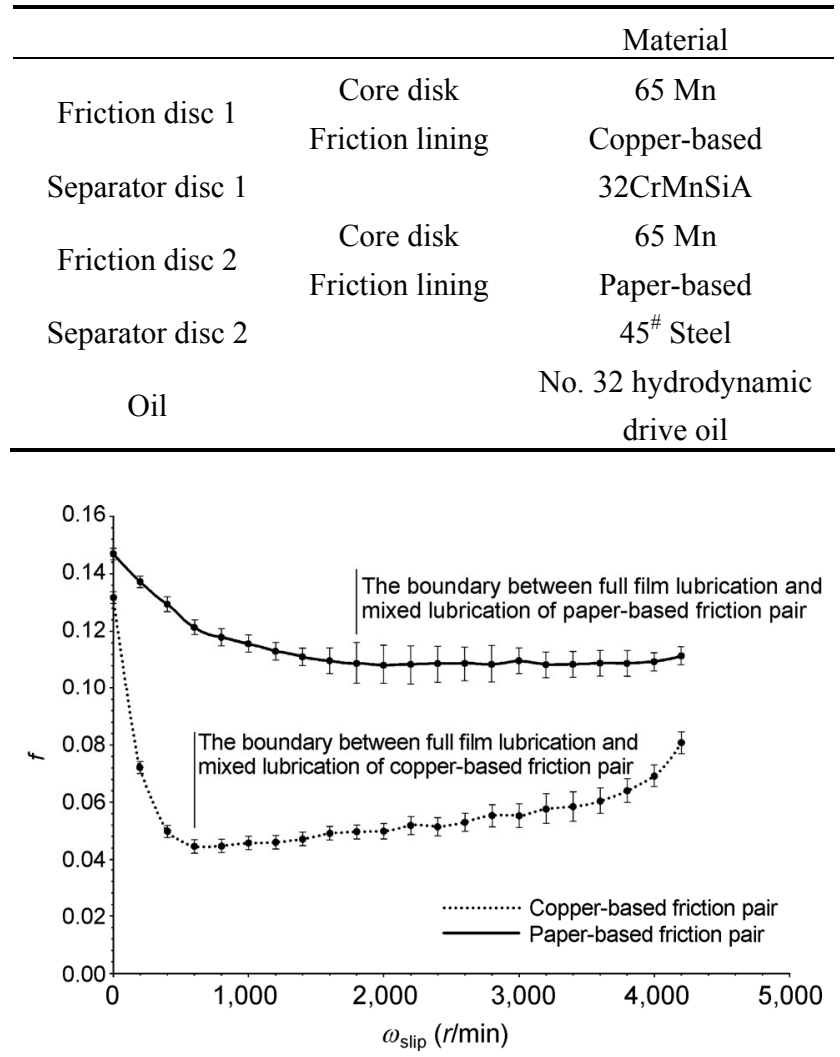

Fig. 3 The friction coefficient-slipping speed curves from the tests.

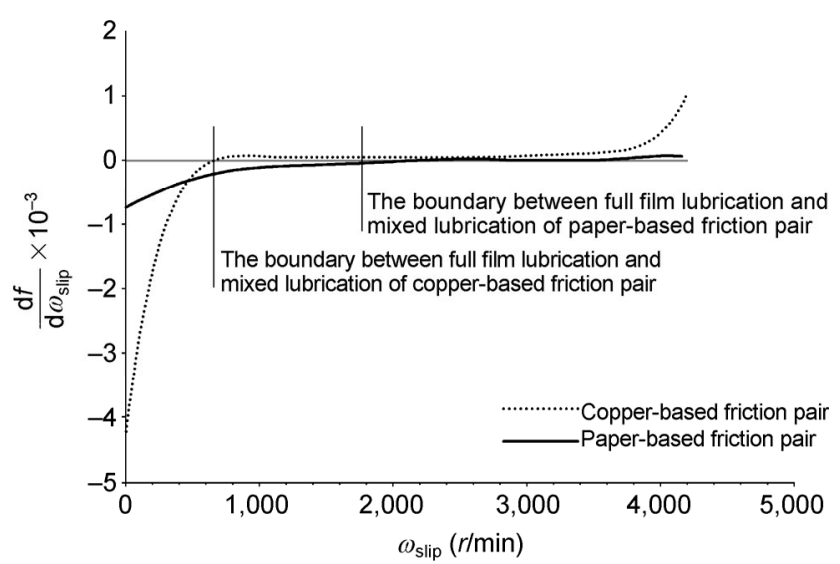

Fig. 4 The calculated derivative curves of the friction coefficient- slipping speed shown in Fig. 3.

The friction coefficient of the paper-based friction pair has a smaller range than the friction coefficient of the copper-based friction pair. However when the two types of friction pairs are tested at the same relative rotational speed, the friction coefficient of the paper-based friction pair is always larger than that of the copper-based friction pair.

\section{Torsional vibration model in mixed lubrication}

The friction pairs of an HVC transfer torque from an engine to a vehicle driveline. Under conditions where the friction pairs are slipping, the engine and driveline speeds are unequal, but the frictional torque, $T_{\mathrm{f}}$, in the friction interface is equal but acts in the opposite direction of the engine and driveline. As shown in Fig. 5, the engine and driveline points are related by the horizontal line in the figure, which represents the balance points of an HVC. Also, the engine power, $W_{\text {engine }}=T_{\mathrm{f}} \cdot \omega_{\mathrm{s}}$, is balanced by the combination of the driveline power, $W_{\text {driveline }}=T_{\mathrm{f}} \cdot \omega_{\mathrm{L}}$, and the frictional heat power, $W_{\text {heat }}=T_{\mathrm{f}} \cdot\left(\omega_{\mathrm{s}}-\omega_{\mathrm{L}}\right)$.

Figure 6 illustrates the torsional vibration model of the system, including the engine, the input axis, friction discs, separator discs, the output axis and the vehicle driveline. In the model, the torsional stiffness of the input axis and the output axis, and the damping of the friction discs and separator discs are considered, but the damping of the engine and the vehicle driveline are ignored.

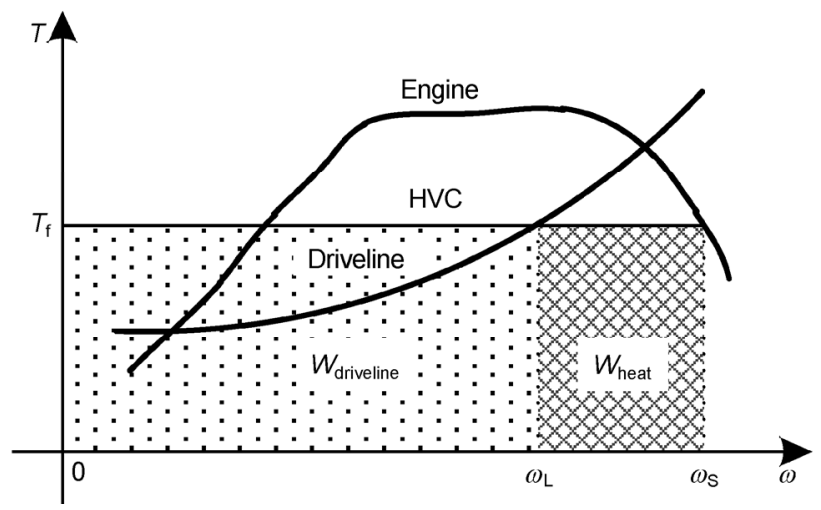

Fig. 5 Schematic of the balance points of an HVC.

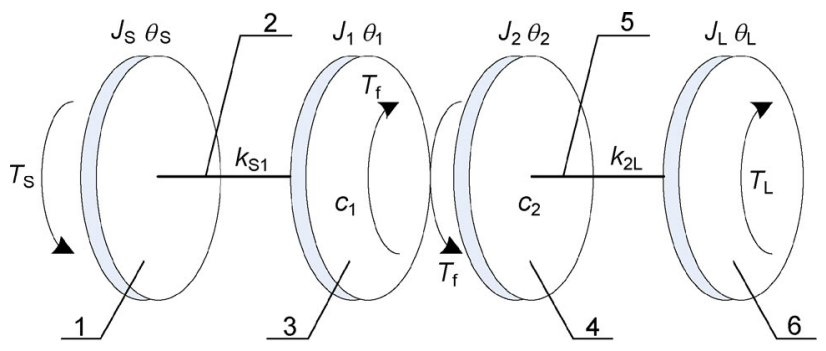

Fig. 6 A schematic of the torsional vibration model of the system: 1-Engine; 2-Input axis; 3-Friction disc; 4-Separator disc; 5-Output axis; 6-Vehicle driveline. 
In mixed lubrication, the contact zone of the friction pair can be divided into a lubricated area, where the friction disc and separator disc are separated by a lubricant film, and an asperity area, where the two surfaces are in direct contact. Thus, the frictional torque in mixed lubrication, $T_{\mathrm{f}}$, can be given as a combination of the hydrodynamic torque, $T_{h}$, and the asperity torque, $T_{a}$, as follows in Eq. (1).

$$
T_{\mathrm{f}}=T_{\mathrm{h}}+T_{\mathrm{a}}
$$

The asperity torque, $T_{a}$, changes as a function of the film thickness. The ratio $\lambda$ of the film thickness, $h$, and the standard deviation of the combined roughness, $\sigma$, is defined as $\lambda=h / \sigma$.

As for plane contact, it is assumed that two peaks of asperity come into contact and that the asperities do not tilt. Under these conditions, Greenwood and Tripp [16] defined the actual contact area ratio, $k_{a}$, based on the Greenwood and Williamson (GW) model as

$$
k_{\mathrm{a}}=\pi^{2}\left(\eta_{\mathrm{p}} R_{\mathrm{p}} \sigma\right)^{2} F_{2}(\lambda)
$$

where $\eta_{\mathrm{p}}$ is the peak density of the friction plate and separator disk, for $\eta_{\mathrm{p}}=7 \times 10^{7} \mathrm{~m}^{-2}, R_{\mathrm{p}}$ is the curvature radius of asperity, for $R_{\mathrm{p}}=8 \times 10^{-4} \mathrm{~m}$, and, for the deformation of asperity $\delta, F_{2}(\lambda)$ is given by:

$$
F_{2}(\lambda)=\int_{\lambda}^{\infty}(\delta-\lambda)^{2} \phi(\delta) \mathrm{d} \delta
$$

Here, it is assumed the asperity peak density is a Gaussian distribution, and the probability density function of the asperity peak is

$$
\phi(\delta)=\frac{1}{\sigma \sqrt{2 \pi}} \mathrm{e}^{-\frac{\delta^{2}}{2 \sigma^{2}}}
$$

The real contact area ratio is

$$
k_{\mathrm{a}}=\frac{\pi^{2}\left(\eta_{\mathrm{p}} R_{\mathrm{p}} \sigma\right)^{2}}{2}\left[\left(1+\lambda^{2}\right) \cdot \operatorname{erfc}\left(\frac{\lambda}{\sqrt{2}}\right)-\sqrt{\frac{2}{\pi}} \lambda \mathrm{e}^{-\frac{\lambda^{2}}{2}}\right]
$$

where $\operatorname{erfc}(\cdot)$ is the Gaussian complementary error function, $\operatorname{erfc}(x)=\frac{2}{\sqrt{\pi}} \int_{x}^{\infty} \mathrm{e}^{-\eta^{2}} \mathrm{~d} \eta$.

The contact peaks of asperity are assumed to undergo elastic deformation and to be of a uniform distribution. Therefore, based on Hertz contact theory, the asperity load of a contact peaks $W_{\mathrm{a}}$ is

$$
W_{\mathrm{a}}=\frac{4}{3} k_{\mathrm{a}} A_{\mathrm{a}} E R^{\frac{1}{2}} \delta^{\frac{3}{2}}
$$

where $A_{\mathrm{a}}$ is the nominal contact area, $E$ is the equivalent elastic modulus, and $R$ is the curvature radius of asperity.

Taking the separator discs into consideration in the torsional vibration model, the torsional vibration equation is expressed as

$$
J_{2} \ddot{\theta}_{2}+c_{2} \dot{\theta}_{2}+k_{2 \mathrm{~L}} \theta_{2}=T_{\mathrm{f}}+k_{2 \mathrm{~L}} \theta_{\mathrm{L}}=T_{\mathrm{h}}+T_{\mathrm{a}}+k_{2 \mathrm{~L}} \theta_{\mathrm{L}}
$$

When the friction discs and separator discs are nearly engaged in mixed lubrication, where the film between the friction pair is thin and greatly diminished, the hydrodynamic torque can be ignored. Under these conditions, the torsional vibration equation of the separator discs can be simplified as

$$
J_{2} \ddot{\theta}_{2}+c_{2} \dot{\theta}_{2}+k_{2 \mathrm{~L}} \theta_{2}=T_{\mathrm{a}}+k_{2 \mathrm{~L}} \theta_{\mathrm{L}}
$$

where the asperity torque $T_{a}$ is given by Eq. (9), which is formulated by the asperity load $W_{a}$, friction coefficient $f_{\mathrm{a}}\left(\omega_{\text {slip }}\right)$, and the mean radius of the friction pair $R_{\mathrm{m}}$.

$$
T_{\mathrm{a}}=W_{\mathrm{a}} f_{\mathrm{a}}\left(\omega_{\text {slip }}\right) R_{\mathrm{m}}
$$

The asperity load is the load of asperity contact between the friction disc and separator disc in Eq. (6), and the friction coefficient is obtained by the tests described in Section 2. Thus, the torsional vibration equation of the separator discs is expressed as

$$
J_{2} \ddot{\theta}_{2}+c_{2} \dot{\theta}_{2}+k_{2 \mathrm{~L}} \theta_{2}=W_{\mathrm{a}} f_{\mathrm{a}}\left(\omega_{\text {slip }}\right) R_{\mathrm{m}}+k_{2 \mathrm{~L}} \theta_{\mathrm{L}}
$$

\section{Stability analysis}

At a balance point of the torsional vibration model of the system, $\dot{\theta}_{20}$, Eq. (10) can be expressed as

$$
J_{2} \ddot{\theta}_{20}+c_{2} \dot{\theta}_{20}+k_{2 \mathrm{~L}} \theta_{20}=W_{\mathrm{a}} f_{\mathrm{a}}\left(\omega_{\mathrm{S} 0}\right) R_{\mathrm{m}}+k_{2 \mathrm{~L}} \theta_{\mathrm{L}}
$$

where $\omega_{\mathrm{S} 0}$ represents the relative rotational speed at the balance point, $\dot{\theta}_{20}$. 
We assume that the rotational speed of the friction disc is constant, but the separator disc has a slight fluctuation of rotational speed at balance point, $\dot{\delta}_{2}$, where $\dot{\delta}_{2}=\dot{\theta}_{2}-\dot{\theta}_{20}$. Thus, Eq. (10) can be expressed as

$$
\begin{aligned}
& J_{2}\left(\ddot{\delta}_{2}+\ddot{\theta}_{20}\right)+c_{2}\left(\dot{\delta}_{2}+\dot{\theta}_{20}\right)+k_{2 \mathrm{~L}}\left(\delta_{2}+\theta_{20}\right) \\
= & W_{\mathrm{a}} f_{\mathrm{a}}\left(\omega_{\mathrm{S} 0}-\dot{\delta}_{2}\right) R_{\mathrm{m}}+k_{2 \mathrm{~L}} \theta_{\mathrm{L}}
\end{aligned}
$$

Eq. (12) minus Eq. (11) is

$$
J_{2} \ddot{\delta}_{2}+c_{2} \dot{\delta}_{2}+k_{2 \mathrm{~L}} \delta_{2}=W_{\mathrm{a}}\left[f_{\mathrm{a}}\left(\omega_{\mathrm{s} 0}-\dot{\delta}_{2}\right)-f_{\mathrm{a}}\left(\omega_{\mathrm{s} 0}\right)\right] R_{\mathrm{m}}
$$

Based on the Taylor series extension theory, $f_{\mathrm{a}}\left(\omega_{\mathrm{s} 0}-\right.$ $\dot{\delta}_{2}$ ) becomes:

$$
\begin{aligned}
f_{\mathrm{a}}\left(\omega_{\text {slip }}\right) & =f_{\mathrm{a}}\left(\omega_{\mathrm{s} 0}-\dot{\delta}_{2}\right)=f_{a}\left(\omega_{\mathrm{s} 0}\right)-\frac{\mathrm{d} f_{\mathrm{a}}}{\mathrm{d} \omega_{\text {slip }}} \dot{\delta}_{2} \\
& +\frac{1}{2} \frac{\mathrm{d}^{2} f_{\mathrm{a}}}{\mathrm{d} \omega_{\text {slip }}} \dot{\delta}_{2}^{2}+\cdots
\end{aligned}
$$

By neglecting the higher order terms in Eq. (14) and retaining only the first order term, Eq. (13) can be expressed as

$$
J_{2} \ddot{\delta}_{2}+\left(c_{2}+W_{\mathrm{a}} R_{\mathrm{m}} \frac{\mathrm{d} f_{\mathrm{a}}}{\mathrm{d} \omega_{\text {slip }}}\right) \dot{\delta}_{2}+k_{2 \mathrm{~L}} \delta_{2}=0
$$

Taking $\ddot{\delta}_{2}$ as $\dot{\delta}_{2} \frac{\mathrm{d} \dot{\delta}_{2}}{\mathrm{~d} \delta_{2}}$, Eq. (15) becomes:

$$
\frac{\mathrm{d} \dot{\delta}_{2}}{\mathrm{~d} \delta_{2}}=-\frac{\left(c_{2}+W_{\mathrm{a}} R_{\mathrm{m}} \frac{\mathrm{d} f_{\mathrm{a}}}{\mathrm{d} \omega_{\text {slip }}}\right) \dot{\delta}_{2}-k_{2 \mathrm{~L}} \delta_{2}}{J_{2} \dot{\delta}_{2}}
$$

Thus, the equations that calculate the singular point of Eq. (15) by the phase plane analysis method are given by Eq. (17).

$$
\left\{\begin{array}{c}
\left(c_{2}+W_{\mathrm{a}} R_{\mathrm{m}} \frac{\mathrm{d} f_{\mathrm{a}}}{\mathrm{d} \omega_{\text {slip }}}\right) \dot{\delta}_{2}-k_{2 \mathrm{~L}} \delta_{2}=0 \\
J_{2} \dot{\delta}_{2}=0
\end{array}\right.
$$

The only real solutions of Eq. (17) are given by Eq. (18).

$$
\left\{\begin{array}{l}
\delta_{2}=0 \\
\dot{\delta}_{2}=0
\end{array}\right.
$$

In other words, balance point, $\dot{\theta}_{20}$, is the only singular point of the system.

To analyze the stability of the model, Eq. (15) can be rewritten as

$$
\ddot{\delta}_{2}+B \dot{\delta}_{2}+C \delta=0
$$

where

$$
\begin{gathered}
B=\frac{c_{2}+W_{\mathrm{a}} R_{\mathrm{m}} \frac{\mathrm{d} f_{\mathrm{a}}}{\mathrm{d} \omega_{\text {slip }}}}{J_{2}} \\
C=\frac{k_{2 \mathrm{~L}}}{J_{2}}>0
\end{gathered}
$$

The characteristic equation of Eq. (15) is

$$
S^{2}+B S+C=0
$$

and the characteristic roots are

$$
S_{1,2}=\frac{-B \pm \sqrt{B^{2}-4 C}}{2}
$$

The distribution of singularities on the phase plane is illustrated in Fig. 7, where $B$ is set as the abscissa and $C$ as the ordinate.

From Eqs. (20) and (21), the parameters $B$ and $C$ are related to the friction characteristics of the friction pair, $W_{\mathrm{a}} \frac{\mathrm{d} f_{\mathrm{a}}}{\mathrm{d} \omega_{\text {slip }}}$, the size of the friction pair, $R_{\mathrm{m}}$, and the structure parameters of the system, such as $J_{2}, c_{2}$, and $k_{2 \mathrm{~L}}$.

The critical negative gradient $(\mathrm{CNG}), m=c_{2} /$ $\left(W_{\mathrm{a}} R_{\mathrm{m}}\right)$, is then defined, which is a function of the

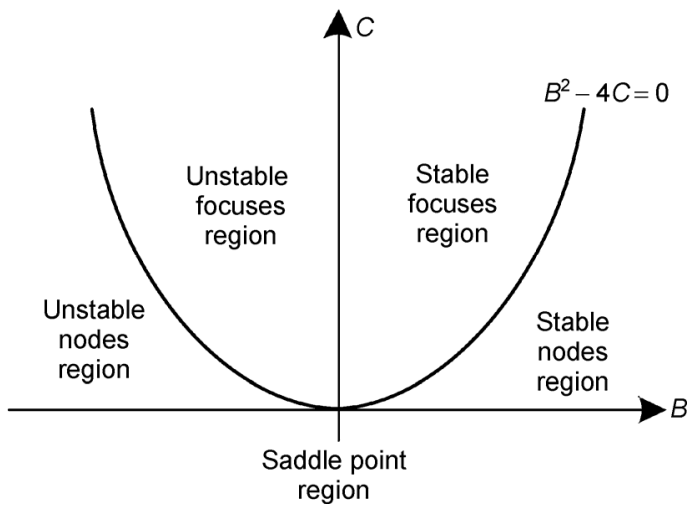

Fig. 7 Schematic of the distribution of singularities on the phase plane. 
equivalent viscosity damping coefficient $c_{2}$, asperity load $W_{\mathrm{a}}$, and the mean radius of friction pair $R_{\mathrm{m}}$.

In mixed lubrication, $\mathrm{d} f_{\mathrm{a}} / \mathrm{d} \omega_{\text {slip }}$ is always negative. When $-m \leqslant \mathrm{~d} f_{\mathrm{a}} / \mathrm{d} \omega_{\text {slip }}<0, C$ and $B$ are positive in Eqs. (20) and (21). As shown in Fig. 7, Eq. (19) is in the stable region, that is to say, Eq. (11) is in the stable region and the rotational speed of the system remains stable.

When $\mathrm{d} f_{\mathrm{a}} / \mathrm{d} \omega_{\text {slip }}<-m, C$ is positive but $B$ is negative, as shown in Fig. 7. For $B^{2}-4 C<0$, Eq. (23) is conjugate complex roots that have a positive real part, and the singular point is an unstable focus and the transient is a divergent oscillation process, where the series spirals away from the singular point, as shown in Fig. 8. For $B^{2}-4 C>0$, Eq. (23) is positive real roots, and the singular point is an unstable node and the transient is a monotonic divergent process, where the series of lines lie far away from the singular point, as shown in Fig. 9.

Thus, the stability regions of the copper-based and the paper-based friction pairs are shown in Fig. 10. For the paper-based friction pair, the HVC will be unstable when the relative rotational speed is below $\omega_{1}$, and, for copper-based friction pair, the HVC will be unstable when the rotational speed is below $\omega_{2}$. Increasing the CNG is an efficient way to improve the rotational speed stability of an HVC in mixed lubrication. From the definition equation of CNG, $m=c_{2} /\left(W_{\mathrm{a}} R_{\mathrm{m}}\right)$, and the above analyses, the CNG

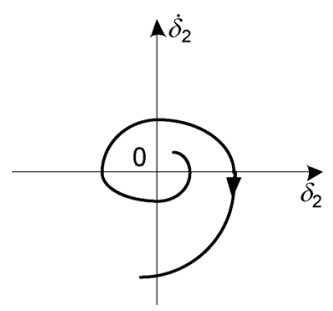

Fig. 8 The phase plane of an unstable focus.

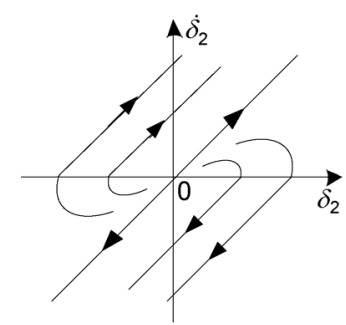

Fig. 9 The phase plane of an unstable node.

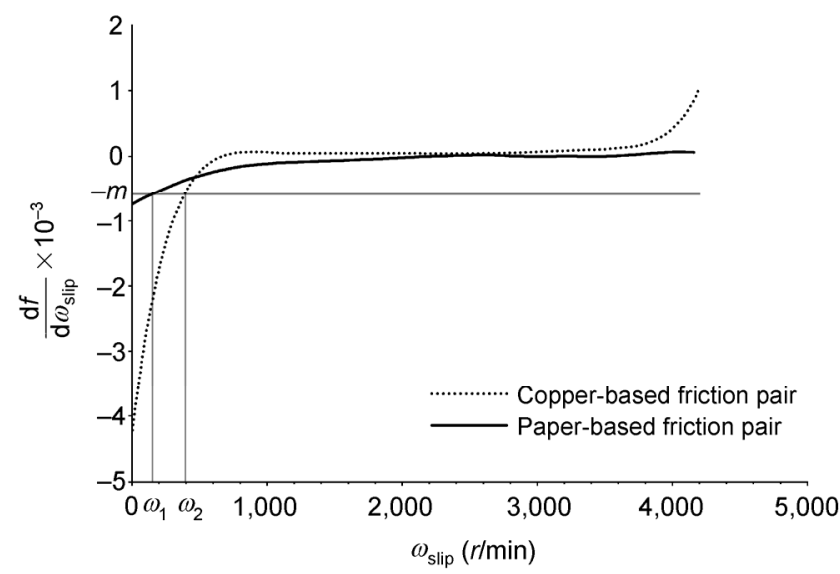

Fig. 10 A stable region marked by the $\mathrm{CNG}$ on the calculated derivative of the friction coefficient-slipping speed curves.

can be increased by increasing $c_{2}$, the equivalent viscosity damping coefficient of the separator discs, or by decreasing $R_{\mathrm{m}}$, the mean radius of the friction pair.

\section{Conclusions}

The rotational speed stability of an HVC in mixed lubrication was studied experimentally and theoretically to reveal the frictional effects on the speed stability in an effort to improve it.

The friction coefficient-slipping speed curves of both copper-based and paper-based friction pairs were tested with a MM1000-III wet friction machine. From the tests, the negative gradient of the friction coefficient of the paper-based friction pair was observed to be smaller than that of the copper-based friction pair.

In an HVC, the frictional torques of the friction disc and the separator disc are equal, but the speeds are different. The torsional vibration model of the system was established according to these characteristics. The phase plane analysis method was used to analyze the stability of the torsional vibration equation, and the CNG was defined, which provided a better means to evaluate the rotational speed stability of an HVC than that provided by the negative gradient.

The results show the following:

(1) In mixed lubrication, the negative gradient of the friction coefficient-slip speed is an important parameter for the stability of the rotational speed. The system remains stable when the negative gradient is less than the CNG. 
(2) Choosing a type of friction pair material that has a smaller negative gradient in mixed lubrication is a useful way to improve the stability of an HVC, such as choosing a paper-based friction pair rather than a copper-based friction pair.

(3) Increasing the CNG on the premise of a perfect performance of an HVC can make the negative gradient of the friction pair in mixed lubrication less likely to exceed the $\mathrm{CNG}$, thus improving the rotational speed stability of an HVC. According to the definition of the CNG, the stability of an HVC can be improved by increasing the equivalent viscosity damping coefficient of the separator discs, $c_{2}$, or decreasing the mean radius of the friction pair, $R_{\mathrm{m}}$.

\section{Acknowledgements}

This project is supported by National Natural Science Foundation of China (Grant No. 51275039) and Tribology Science Fund of the State Key Laboratory of Tribology (Grant No. SKLTKF13B01). The authors would like to express gratitude to Xi'an Kenai Friction Material Co. Ltd. for providing MM1000-III tester and assisting in doing the friction characteristic tests.

\section{Nomenclature}

$c_{1}$ Equivalent viscous damping coefficient of friction $\operatorname{discs}[(\mathrm{N} \cdot \mathrm{m}) /(\mathrm{rad} \cdot \mathrm{s})]$

$c_{2}$ Equivalent viscous damping coefficient of separator $\operatorname{discs}[(\mathrm{N} \cdot \mathrm{m}) /(\mathrm{rad} \cdot \mathrm{s})]$

$f$ Friction coefficient $[\mathrm{N} \cdot \mathrm{m}]$

$f_{\mathrm{a}}\left(\omega_{\text {slip }}\right)$ Friction coefficient of an asperity contact, which is a function of $\omega_{\text {slip }}$

$J_{1}$ Moment of inertia of the HVC friction discs $\left[\mathrm{kg} \cdot \mathrm{m}^{2}\right]$

$\mathrm{J}_{2}$ Moment of inertia of the HVC separator discs $\left[\mathrm{kg} \cdot \mathrm{m}^{2}\right]$

$J_{\mathrm{L}}$ Moment of inertia of the vehicle driveline $\left[\mathrm{kg} \cdot \mathrm{m}^{2}\right]$

$J_{\mathrm{S}}$ Moment of inertia of the engine $\left[\mathrm{kg} \cdot \mathrm{m}^{2}\right]$

$k_{2 \mathrm{~L}}$ Equivalent torsional stiffness of output axis $[(\mathrm{N} \cdot \mathrm{m}) / \mathrm{rad}]$

$k_{\mathrm{s} 1}$ Equivalent torsional stiffness of input axis [(N.m) / rad]

$R_{1}$ Inner diameter of friction pair [mm]
$R_{2}$ Outer diameter of friction pair [mm]

$R_{\mathrm{m}}$ mean radius of friction pair [mm], where $R_{m}=$ $\frac{R_{1}+R_{2}}{2}$

$T_{\mathrm{a}}$ Asperity torque $[\mathrm{N} \cdot \mathrm{m}]$

$T_{\mathrm{f}}$ Frictional torque $[\mathrm{N} \cdot \mathrm{m}]$

$T_{\mathrm{h}}$ Hydrodynamic torque $[\mathrm{N} \cdot \mathrm{m}]$

$T_{\mathrm{L}}$ Vehicle driveline torque $[\mathrm{N} \cdot \mathrm{m}]$

$T_{\mathrm{S}}$ Engine torque $[\mathrm{N} \cdot \mathrm{m}]$

$W_{a}$ Asperity load of friction pair in mixed lubrication [N]

$\omega_{\text {slip }}$ Relative angular rotational speed between the friction pair $[\mathrm{rad} / \mathrm{s}]$

$\omega_{S}$ Angular velocity of the engine crack shaft $[\mathrm{rad} / \mathrm{s}]$

$\omega_{\mathrm{L}}$ Angular velocity of the vehicle driveline $[\mathrm{rad} / \mathrm{s}$ ]

$\theta_{\mathrm{S}}$ Rotational angle of the engine [rad]

$\theta_{\mathrm{L}}$ Rotational angle of the vehicle driveline [rad]

$\theta_{1}$ Rotational angle of friction discs [rad]

$\theta_{2}$ Rotational angle of separator discs [rad]

Open Access: This article is distributed under the terms of the Creative Commons Attribution License which permits any use, distribution, and reproduction in any medium, provided the original author(s) and source are credited.

\section{References}

[1] Cho J H, Schultz W W, Ceccio S L, Yoshioka T, Hiraki H. Modeling and parametric study of torque in open clutch plates. ASME J Tribol 128(2): 422-430 (2006)

[2] Zhou M-S, Zhang Y. Theoretical research on hydroviscous speed-adjusting clutch in soft-start of belt conveyor. J Coal Sci Eng 11(1): 79-82 (2005)

[3] Huang J-H, Fan Y-R, Qiu M-X. Effects of groove on behavior of flow between hydro-viscous drive plates. J Cent South Univ Tech 19: 347-356 (2012).

[4] Sojoudi H, Khonsari M M. On the behavior of friction in lubricated point contact with provision for surface roughness. J Tribol 132 (1): 012102 (2009)

[5] Cameron T M, Devlin M T, McCombs T, Rollin A J, Tersigni S H, Jao T-C. Clutch parameter effects on torque and friction stability. SAE Technical Paper 2011-01-0722 (2011)

[6] Patir N, Cheng H S. An average flow model for determining effects of three dimensional roughness on partial hydrodynamic lubrication. ASME J Lubr Technol 100(1): 12-17 (1978) 
[7] Lu X B, Khonsari M M, Gelinck E R M. The Stribeck curve: Experimental results and theoretical prediction. $J$ Tribol 128(4): 789-794 (2006)

[8] Lu X B, Khonsari M M. An experimental investigation of dimple effect on the Stribeck curve of journal bearings. Tribol Lett 27(2): 169-176 (2007)

[9] Wang W-Z, Liu Y-C, Wang H. A computer thermal model of mixed lubrication in point contacts. $J$ Tribol 126(1): 162-170 (2004)

[10] Wang W-Z, Wang S, Shi F H. Simulations and measurements of sliding friction between rough surfaces in point contacts: From EHL to boundary lubrication. J Tribol 129(3): 495501 (2007)

[11] Masjedi M, Khonsari M M. Film thickness and asperity load formulas for line-contact elastohydrodynamic lubrication with

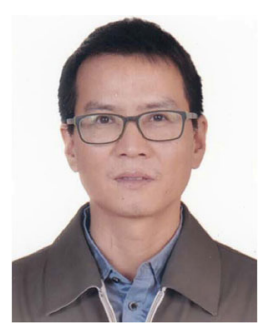

Shou-Wen YAO. He received his Ph.D degree from China Academy of Railway Sciences, China, in 2000. $\mathrm{He}$ is currently an associate pro-

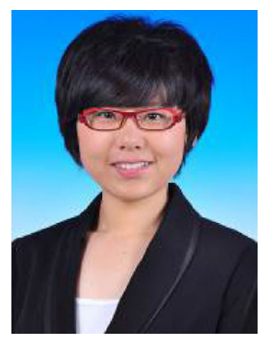

Qian LIU. She received her Bachelor degree in School of Mechanical Engineering and Automation in 2012 from Northeastern University, China. She is currently a graduate

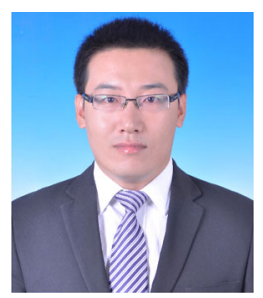

Hong-Wei CUI. He received his bachelor degree in School of Mechanical Engineering at Beijing Institute of Technology, China, in 2008. And then, he received his

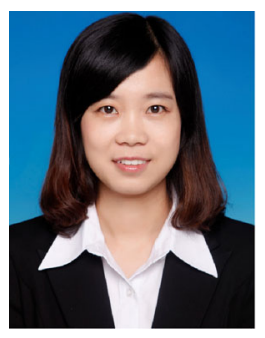

Shan-Shan FENG. She received her Bachelor degree in School of Transportation in 2011 from Ludong University, China. She is provision for surface roughness. J Tribol 134(1): $011503-$ 011512 (2012)

[12] Huang X G, Wei C G. Stability of oil film and output speed of hydroviscous drive affected by the pressure of control oil. J Beijing Institute Tech 10(3): 226-271 (2001)

[13] Berger E J. An investigation of friction-induced vibration in automatic transmission wet clutches. Ph. D. Thesis. Purdue University, 1996.

[14] Huron G. Numerical Simulation of SAE\#2 Ma-chine Tests. SAE Technical Paper 1999-01-3617 (1999)

[15] Gao H, Barber G C, Shillor M. Numerical simulation of engagement of a wet clutch with skewed surface roughness. J Tribol 124: 305-312 (2002)

[16] Greenwood J A, Tripp J H. The elastic contact of rough spheres. J Appl Mech 34:153-159 (1967)

fessor in School of Mechanical Engineering at Beijing Institute of Technology, China. His research interests include the technology of vehicular transmission, viscous drive, etc.

student in School of Mechanical Engineering at Beijing Institute of Technology. Her research interests include the technology of vehicular transmission and viscous drive.

Ph.D degree at the same university. He is currently a teacher in School of Mechanical Engineering at Taiyuan University of Technology. His research interests include the technology of vehicular transmission and viscous drive.

currently a graduate student in School of Mechanical Engineering at Beijing Institute of Technology. Her research interests include the technology of vehicular transmission and viscous drive. 